\title{
The Impact of Artificial Intelligence on Accounting
}

\author{
Zehong Li \\ Department of Economics and Management \\ North China Electric Power University \\ Baoding, 071003, China \\ lizehong2003@sohu.com
}

\author{
Li Zheng \\ Department of Economics and Management \\ North China Electric Power University \\ Baoding, 071003, China \\ 1030008516@qq.com
}

\begin{abstract}
With the rapid development of economy, science and technology, the era of artificial intelligence has come, which has exerted a great influence on all aspects of life. Whether the situation of accountants facing elimination is widely concerned. This article will be focusing on how to use artificial intelligence to avoid accounting fraud and to generate positive impact on accounting information quality, this article will analyze how artificial intelligence will effect the accounting personnel, but decisions can't be made by machine, so it won't cause a mass unemployment. The end of the article will underline that in the big picture of artificial intelligence, accounting personnel should improve its own seven aspects of abilities and become a comprehensive qualified personnel.
\end{abstract} impact

Keywords-Artificial intelligence; Accounting profession;

\section{INTRODUCTION}

In recent years, the rapid development of artificial intelligence technology has attracted worldwide attention. With the rapid development of AI technology, you will find that artificial intelligence has its impact on almost every corner of the world, from a simple replacement of human labor to gradually affect people's daily life. According to a survey, most likely, most jobs will be handled to robots in the next 20 years including low-end manufacturing production, sales and accounting. Therefore, basic accounting practitioners are one of the groups that will be affected by artificial intelligence.

\section{THE ORIGIN AND PRINCIPLE OF ARTIFICIAL INTELLIGENCE}

The term "artificial intelligence" was first brought up at the $\mathrm{D}$ art mouth seminar at 1956. Since then, researchers have developed many theories and principles, and the concept of artificial intelligence has also been expanded. Artificial intelligence, in essence, is a simulation of the process of thinking and information obtaining ${ }^{[1]}$. Human thinking simulation can be carried out in two ways. First, structural simulation can imitate the structural mechanism of the human brain and create a "brain-like" machine. The second one is called functional simulation, which will temporarily leaves out the internal structure of the human brain and simulates from its functional process. The modern electronic computer is a simulation of the brain's thinking function and the information process.

\section{THE IMPACT OF ARTIFICIAL INTELLIGENCE ON THE ACCOUNTING INDUSTRY}

In the era of artificial intelligence, traditional accounting personnel will leave a few more complicated tasks to the accounting software to complete, this will greatly improve the working efficiency, reduces the working error, improve the competitiveness of the enterprises, the accounting industry, this will also be conducive to promote the transformation of the accounting industry ${ }^{[2]}$.

\section{A. Avoid the possibility of financial fraud}

In those traditional accounting positions, incompatible positions are not actually separated, especially in small and medium-sized enterprises, financial personnel will have access in both cash flow and the bookkeeping, so there will be disorder accounts in financial accounting, and of course financial fraud, self-serving criminals are given the opportunity to benefit themselves. The management level has the authority over the internal control, which will cause harm to the relevant interests parties like shareholders and this situation is not conducive to the long-term development of the enterprise. However, in the environment of artificial intelligence, a large amount of accounting and other work will be handed over to the computer to complete; accounting personnel only need to review it. At the end of the period, the system will settle the bill automatically and carry out the trial balance. In the accounting system, each accounting personnel has its own corresponding privileges, and has different accounts and passwords, a clear separation of responsibilities, so to a certain extent, this will reduce the possibilities of financial fraud. Accounting system, however, this still cannot solve the financial fraud from happening in the source, because any system have to be controlled by people, eventually the settings of permissions is done through people, so by using accounting system can not put an end to the management above the internal control.

\section{B. Improve the quality of accounting information}

In the traditional accounting position, from the making of accounting vouchers, the registration of accounting books, to the formation of statements, the accounting personnel will have to check all these procedures. But, on the one hand, it took a lot of manpower, material resources and financial resources, the efficiency is low, tasks won't be finished like scheduled, even though it will be finished on time, it will be the result of overtime working; On the other hand, as a result of long hours of work, it is hard to avoid fatigue and mistakes, resulting in 
the distortion of accounting information. When an enterprise uses accounting software to do accounting, on the one hand, all financial procedures can be completed in time, which improves the efficiency of the work. Financial personnel only need to do the audit in the accounting system. On the other hand, by using the accounting software, accounting personnel only need to input data, then leave the process to the computer to complete, although there could also be errors when the accounting personnel try to input the financial data, but when you have a wrong data entry, the accounting software system will automatically report the error, which will greatly reduces the working error, improve the quality of accounting information.

\section{Promote the reform of traditional accounting and auditing}

In the traditional accounting profession, the job duties of accounting personals are divided according to the business process, but under the circumstances of artificial intelligence, AI will take the place of traditional accounting and auditing work, improving the work efficiency greatly, changing the method of separation of traditional accounting and auditing work, this will help accounting personnel to improve their own work quality and ability. This will also optimize the setting of accounting posts, optimize the structure layout, and change the traditional financial and practical working modes. At the same time, the artificial intelligence may appear new problems in the accounting industry, so that the targeted solutions can be brought up. As the application of artificial intelligence in the accounting industry becomes more and more extensive, the traditional accounting posts do not need so many employees, which is an obvious change. The history of computerized accounting in our country begins as early as the 1980s, so far, it has been commercialized, used by all kinds of accounting entities, forcing those originally simple accounting records and accounting work replaced by artificial intelligence, accordingly, most positions of accounting personnel are no longer needed.

\section{THE IMPACT OF ARTIFICIAL INTELLIGENCE ON ACCOUNTANTS}

With the automation of all accounting process, intelligent decision making, and accounting service sharing, accounting basic work flow will be more professional on one hand, on the other hand, a large number of procedural accounting basic work will be replaced by accounting information system, which leads to the transformation of the accounting personnel, that is, from the fecundation, procedure, repeatability of accounting work, to more valuable and more professional judgment, based on large data analysis and data mining such as accounting management ${ }^{[3]}$. With the ascension of information and personnel costs, coupled with the rise of big data, such as financial Shared services center, it is very likely to reduce the number of accounting personnel; maybe most of the basic accounting personnel will face a similar fate with dinosaurs. With the continuous development of science and technology, artificial intelligence is gradually replacing some part of the accounting personnel; in this case, the enterprises will gradually reduce the demand for accounting personnel in the accounting department, making the accounting personnel face the crisis of elimination.

In fact, accounting personnel don't have to panic, as long as you are no longer using the old ways of working, and willing to be a so-called "robot accountants", then, transforming to the automatic accounting for most accountants is actually a good news. The so-called "robot accountant" refers to professional financial personnel who use automation technology to perform time-consuming, redundant and repeatable data entry tasks and interact with such automation technology. While using these automation technologies, they will also help enterprises make business decisions based on their own experiences. Technology alone cannot lead the future. The key is how people can make good use of new technology to make it more valuable in a long-term base. As automation begins to replace accounting tools of the past, the task of accountants will no longer be to just transcribe data, but to interpret it and pass it on to customers. In this new era, accountants should no longer be people who can only use tools, but should be an important part of providing customers with solutions.

This paper further analyzes the irreplaceability of accountants from the two main branches of accounting system: financial accounting and management accounting ${ }^{[4]}$.

\section{A. Financial accounting}

One, liabilities: The accounting standards for enterprises basic standards "(2006) article 23 gives the definition of debt: liabilities are formed by the past transactions or events of an enterprise, it is expected to lead to the economic benefits from the present obligations of the company. Record a number as a liability, you need to determine whether it meet the definition of liabilities first, the financial and accounting personnel will have to use professional knowledge and experience to judge the enterprise, and also has to assume the obligation under the current conditions, the analysis for the foreseeable future will lead to economic benefits from the enterprise and can prove that the amount produced by past transactions or phenomenon. In addition, the definition of debt needs to meet two conditions at the same time: with the obligations related economic interests are likely to flow out; the amount of future outflow of economic benefits can be measured reliably. That is standing under the current management status of future outflow of economic forecasting, also, accounting personnel will get data from the subjective consciousness to measure of the possibility of occurring events, their awareness of and sensitivity to changes in economic environment will determine whether or not the forecast was accurate and reliable, it will eventually affect the results of the enterprise's financial report. Robots can't do the work completely independently, because it can't perceive the changes in the enterprise internally and externally, it only can carry on the digital Numbers which will be used to express liabilities, centralized data more quickly. Enterprise will restructure a plan, for example, if the estimated cost of restructuring obligations cannot be calculated on time, this will hide the debt of the company, also generate effect on the company's future financial activities.

Two, selection of accounting estimates: Accounting estimation refers to the judgment made by an enterprise on transactions or events with uncertain results on the basis of recently used information. Accounting estimates is due to the financial personnel to obtain information from a possible or changing environment, some transactions and events cannot be decided immediately, they need to take account of 
environmental uncertainty, some accounting estimate will be changed as the change of environment, so it can provide more reliable accounting information. Accounting standards stipulate that enterprises should adopt future applicable law to deal with changes in accounting estimates. For example, when an enterprise initially withdraws the bad debt provision with $8 \%$ of the balance of accounts receivable, it should increase the proportion of the bad debt provision and reduce the profit when customers have serious cash flow shortage. The risks to shareholders and investors are not fully and objectively demonstrated if the company does not report the increased bad debt provision. The current formula of artificial intelligence can only performed by using certain set of calculus, it will need accounting personnel to make decisions according to the change of external environment, it also illustrates the accounting personnel to participate in the decision-making of the enterprise.

From two aspects of the above liabilities and accounting estimates, financial accounting from the accounting to finally provide the financial reporting process is not simply to fill in with the operation, but it needs accounting personnel to use their professional knowledge and working experience, combined with the accounting standards and relevant laws and regulations, to provide true and fair financial information to users. Artificial intelligence will be troublesome facilitation and collection of data process, and provide technical support for data analysis process, making accounting personnel repetition a boring job, but when comes to responding to the environment, the final decision will still be made by accounting personnel.

\section{B. Management accounting}

One, participate in business forecasting: Management accounting, according to the past and the present market environment, the related theory and the mathematical model of the future business activities of the enterprise level will change direction based on forecast, for business decision-making. In management accounting of sales forecasting, for example, combined prediction during various external environment present situations and future development trends, combining qualitative analysis and quantitative analysis, analysis of consumers' psychological change and the change of market share, etc. As the market develops under the influence of multiple factors, management accounting needs to modify the initial prediction results to ensure that the predicted results are as good as possible in real conditions.

Two, participate in economic decision-making: When planning the future business activities of enterprises, there will be many alternatives. Management accounting requires rational analysis, comparing the advantages and disadvantages of the plans, and selecting the best ones. When making product features cost decision, for example, compare the features of the product and cost, calculated value, improve the production technology or try to reduce the material cost, in order to achieve the target cost of the enterprise. Artificial intelligence cannot understand the potential correlation between production and operation activities through common sense, induction and reasoning like human beings, so it cannot take the place of financial personnel to participate in economic decision-making process.

Three, participate in performance appraisal and evaluation: When an enterprise grows to a certain scale, its ownership and management rights will belong to shareholders and managers respectively, and there is a principal-agent relationship. In order to evaluate whether managers to maximize shareholders' wealth as their goal, not to seek private interests, to manage the accounting for management performance assessment and evaluation as an important part of internal control study. At this point, management accounting can use accounting robot to build models, simulate the environment to find out uncontrollable factors, more efficient and accurate. Most management activities of enterprises cannot be separated from the participation of management accounting, from budget, decision-making to the final assessment and evaluation of managers' performance. Artificial intelligence can provide information, build models and simulate the future environment to help management accounting accomplish tasks, but it cannot completely replace management accounting to make management decisions.

\section{ACCOUNTANTS FACE THE IMPACT OF ARTIFICIAL INTELLIGENCE}

Although artificial intelligence cannot completely replace accounting, accountants should also actively respond to the impact of artificial intelligence. Therefore, accountants should keep learning in order to improve their professional skills, and at the same time, get involved in management, so as to make themselves a management, intelligent accountant ${ }^{[5]}$.

One, professional ability. That is, the ability of accounting, financial statements and taxation to handle all aspects is the most important thing of many abilities of accountants. As an accountant, if your professional skills are not solid, professional quality is not qualified; this is a problem. Therefore, accountants should keep learning and improving their abilities.

Two, management skills. That is to learn team management and lay a good foundation for future improvement. Mastering management skills may not have much effect on accountants in the short term, but accountants will realize its importance when they take on positions of financial manager or higher.

Three, computer skills. Cloud computing is the hallmark of the current era of big data. The importance of computers has been reflected in the past paper accounting, the present paperless office and the computerized accounting. Therefore, in addition to some simple computer operations, accountants must master certain computer programming techniques to enhance their own data processing capabilities.

Four, analytical capability. That is, the ability to read through statements and control risks easily. Accountants can analyze a lot of financial information through the accounting statement. Therefore, it is very important to analyze and evaluate risks reasonably and accurately.

Five, decision-making ability, that is, the ability to accurately evaluate the quality of a project and improve the 
decision-making ability quickly. During work, financial personnel need to be responsible for financial management, base on the economic environment to determine the condition of the competition, coupled with its own finances, provides reference for enterprises short-term and long-term project decisions and opinions.

Six, the ability to predict, which is, the cost of overall planning, easy to deal with fiscal and tax capacity. Monitor the cost, provide valuable advice to reduce the cost of enterprises, and predict the future economic trend and risk degree of enterprises.

Seven, thinking ability. It is necessary to summarize and improve the ability. For example, think about how to reasonably avoid tax for the enterprise, how to improve the utilization efficiency of funds and so on. This will allow managers to see your value to the business.

Accounting information will bring great changes to the internal management and external survival and development of enterprises. In order to adapt to the development of artificial intelligence, the transformation from finance and accounting work to management and accounting work must be completed by cultivating the talents of compound finance and accounting. Accounting talents should be familiar with accounting theory and practice, is good at IT, at the same time should also be proficient in capital operation, internal control, management, accounting, tax, finance, insurance and other related to accounting in the field of one or more professional knowledge and practical operation, the work involved in all aspects of the strong strain and disposal ability, can in the field of accounting control as the center of a wide range ${ }^{[6]}$. In general, the basic accounting personnel and the entire accounting industry should take the following countermeasures in the future:

One, adapt to the changes of the accounting work situation and realize the transformation from traditional accounting to management accounting: The age of artificial intelligence, robot can efficiently and accurately provide a large number of financial data, which requires the accounting staff acquires professional financial analysis skills, extracted from huge amounts of data are worth to the company's future development of the financial information. Therefore, accountants should change their thinking method actively, abandon the accounting function of traditional accounting, and make a good forecast of the current and future economic prospects of enterprises. Cultivate the ability of management analysis, strengthen the awareness of enterprise management, actively engage in economic activities, achieve management functions, and provide valuable Suggestions and decisions for enterprises.

Two, adapt to the development of science and technology, and find their own value and work target positioning: With the rapid development of artificial intelligence, the need of the accounting industry for interdisciplinary talents has been greatly increased. As accounting personnel, one should not only know how to use artificial intelligence, but also have to acquire corresponding financial data analysis ability, and master relevant knowledge of the business, making big data combined with artificial intelligence and the actual work. As an accounting personnel, therefore, to actively to the development of management accounting and artificial intelligence, improve their professional quality, promote management performance, overall planning and professional ability, improve their strain ability in practical work.

Three, adapt to the development of information and master computer and artificial intelligence related technologies: The application of artificial intelligence will make the work of accountants more valuable, rather than stay in the simple accounting work. Accountants should have the ability to quickly learn and accept new knowledge, and make full use of artificial intelligence. They should understand that the development of science and technology is inevitable. The use of robots is not only beneficial to the development of the accounting profession, accounting industry in the process of development also need the help of artificial intelligence, so as the accounting personnel shall actively adapt to the new change, change their own knowledge framework and thinking mode.

\section{CONCLUSION}

The emergence of artificial intelligence is the result of social and economic development. Artificial intelligence has changed the traditional way of accounting work, but it will not put en end of artificial accounting. The emergence of artificial intelligence is an opportunity, not a challenge, for the accounting industry and accountants. The emergence of artificial intelligence has caused some accountants to lose their jobs to some extent, but in the long run, it will not replace accountants. Which requires the accounting personnel to have a positive view on artificial intelligence, to continuously improve their comprehensive ability, make their efforts to improve their comprehensive ability, to make changes from traditional accounting personnel to a management type, high-end accounting personnel? Accountants should actively adapt to the development of this society, constantly innovate, change themselves, constantly update their knowledge, and become an irreplaceable high-quality accountant.

\section{REFERENCES}

[1] Xing Afeng, tao xuemei, peng ruifeng. Reflections on the accounting industry in the era of artificial intelligence [J]. Accounting and accounting studies,2017(10):112-112.

[2] Huang Jie. "crisis" and "opportunity" of accountants under artificial intelligence [J]. Modern economic information,2016(21).

[3] Mu Yakun, jiang bingyao, zhang xiyue. A brief analysis on how accounting personnel should cope with the impact of artificial intelligence $[\mathrm{J}]$.

[4] Xiang Guifang. Where should accounting go under the rise of artificial intelligence [J]. Modern economic information, 2017(1).

[5] Huang Liucang. Challenges and responses of the development of artificial intelligence to accounting work [J]. Research on education accounting and accounting, 2017, 28(2):3-8.

[6] Ren Mengyu. Study on functional transformation of accounting personnel under artificial intelligence $[\mathrm{J}]$. Modern commercial and trade industry, 2017(23):68-69. 